\title{
Research on ELID Grinding Mechanism and Process Parameter Optimization of Aluminum-Based Diamond Composites for Electronic Packaging
}

https://doi.org/10.1515/secm-2019-0035

Received Sep 07, 2019; accepted Nov 11, 2019

\begin{abstract}
Aiming at the problem of poor processing performance and difficult processing in the process of aluminumbased diamond composites for electronic packaging, this paper uses electrolytic in-process dressing (ELID) grinding technology to grind the aluminum-based diamond composites. The quadratic orthogonal rotation combination method was used to investigate the influence law and degree of grinding depth, grinding wheel linear velocity, duty cycle and electrolysis current on surface roughness. The ELID grinding optimization process parameters of aluminum-based diamond composites obtained by LINGO software are: grinding depth $9.3 \mu \mathrm{m}$, grinding wheel linear speed $36 \mathrm{~m} / \mathrm{s}$, duty cycle $63.7 \%$, electrolysis current $11.5 \mathrm{~A}$. The surface of the aluminum-based diamond composite with a surface roughness of $125 \mathrm{~nm}$ was machined by this optimized process parameter combination.
\end{abstract}

Keywords: ELID grinding; Aluminum-based diamond composite; Quadratic orthogonal rotation combination; Optimized process parameters; Surface roughness

\section{Introduction}

With the rapid development of electronic technology, the integration degree of electronic devices increases. And a

\footnotetext{
^Corresponding Author: Longyue Zhang: College of Mechanical Engineering and Applied Electronics Technology, Beijing Key Laboratory of Advanced Manufacturing Technology, Beijing University of Technology, Beijing 100124, China; Email: 343109962@qq.com; Tel.: 18366969189

Jialiang Guan, Shujun Liu, Yang Yang: College of Mechanical Engineering and Applied Electronics Technology, Beijing Key Laboratory of Advanced Manufacturing Technology, Beijing University of Technology, Beijing 100124, China
}

๑ Open Access. ( 2019 J. Guan et al., published by De Gruyter. (Cc) BY License large amount of heat is generated, which causes the operating temperature of the circuit to be too high, and the electronic device fails.

Traditional electronic packaging materials are not only unable to withstand the damage caused by high heat, nor can they dissipate the high heat generated by electronic devices in time. Therefore, research on new materials for electronic packaging is imminent [1]. Aluminumbased diamond composite is a diamond particle reinforced metal Al-based composite material, which has the advantages of high wear resistance, high specific strength, high specific height, high thermal conductivity and low thermal expansion coefficient. It has become the hottest fourth-generation electronic packaging material, and has broad application prospects in the electronic packaging of aerospace and electronic devices. However, in the traditional cutting process of the aluminum-based diamond composite material, some parts of the aluminum alloy matrix will melt, form a built-up edge, the tool wear becomes dull, resulting in a decrease in roughness. And it is difficult to obtain the high quality machined surfaces, and the corresponding shape and dimensional tolerances are difficult to guarantee. In recent years, most of the research on aluminum-based diamond composite materials is the preparation aspect, using near-net molding technology, laser selection melting technology to reduce secondary processing steps, and direct manufacturing molding technology to solve the shortcomings of difficult processing. However, these technologies are still immature, and the surface quality of the workpieces obtained by applying these techniques in some aerospace and electronic equipment cannot meet the requirements for use [2-5]. Therefore, there is no mature precision ultra-precision machining method for this material. The precision machining research on such composite materials with excellent performance and wide application prospects has practical value for solving major difficult processing problems such as na- 
tional defense, aerospace and electronic component packaging $[6,7]$.

The ELID grinding technology was first proposed by the Institute of Physical and Chemical Research of Japan in the late 1980s. The technology has the advantages of good shape retention of the grinding wheel, sharp repair on the line, high grinding ratio, grinding precision and high grinding efficiency [8-10]. For aluminum-based diamond composites, the hardness of the diamond-reinforced phase is large, and the aluminum matrix phase is very soft. During the ELID grinding process, problems such as prone to burn, serious tool wear and low processing efficiency are generated. This technology can effectively solve these problems and is very suitable for precision mirror grinding of hard and brittle materials and the composites [11, 12].

\section{Physical and chemical properties}

The aluminum-based diamond composite is a particlereinforced phase metal matrix composite formed by uniformly dispersing diamond particles into aluminum [13]. Aluminum-based diamond composites have the advantages of metallic aluminum and diamond materials. Therefore, it has the characteristics of high specific strength, high specific stiffness, high specific modulus, high wear resistance, high thermal conductivity, good fatigue resistance, light weight, low thermal expansion coefficient and good dimensional stability. The sample processed in this experiment is an aluminum-based diamond composite with a diamond particle reinforcement phase volume fraction of $30 \%$ and a diamond particle size of $50 \mu \mathrm{m}$. The mechanical properties and thermal expansion coefficient of the sample were measured using a composite densitometer, an electronic universal tensile tester, and a thermal expansion tester. The measured data are shown in Table 1. The composition of the aluminum-based diamond composites is shown in Figure 1.

Table 1: Performance measurement data of materials

\begin{tabular}{lc}
\hline Volume fraction $/ \%$ & 30 \\
\hline Diamond particle size $/ \mu \mathrm{m}$ & 50 \\
Density $/\left(\mathrm{g} \cdot \mathrm{cm}^{3}\right)^{-1}$ & 3.1 \\
Bending strength/MPa & 200 \\
Compressive strength $/ \mathrm{MPa}$ & 450 \\
Thermal conductivity $/ \mathrm{W} \cdot(\mathrm{m} \cdot \mathrm{k})^{-1}$ & 370 \\
Elastic Modulus $/ \mathrm{GPa}$ & 190 \\
Thermal expansion coefficient $/ \times 10^{-6} \mathrm{~K}^{-1}$ & 7.8 \\
\hline
\end{tabular}

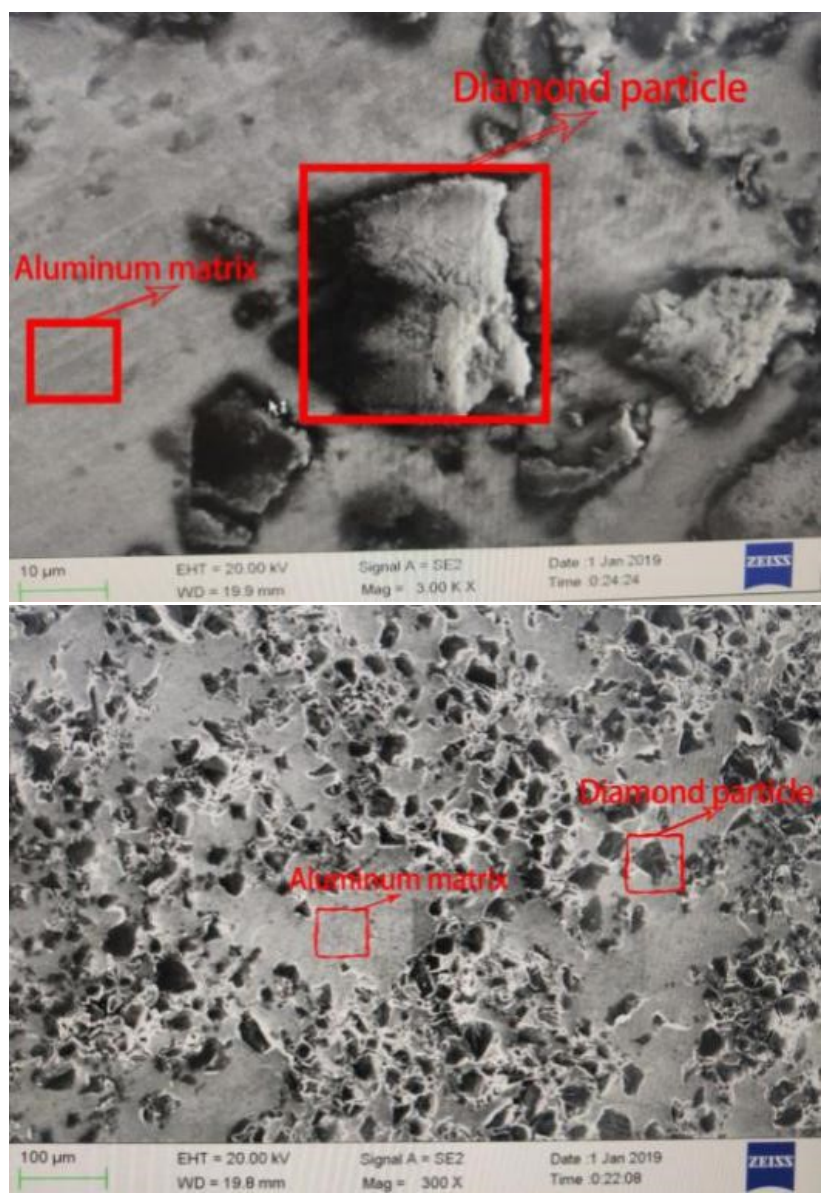

Figure 1: The composition schematic diagram of the material

\section{Mechanism and Advantages of ELID}

\subsection{Grinding Process}

The principle of ELID grinding is shown in Figure 2. The ELID grinding process consists of a power supply, a grinding wheel, an electrode, and a grinding fluid. These parts together form a closed loop that forms an electrolytic reac-

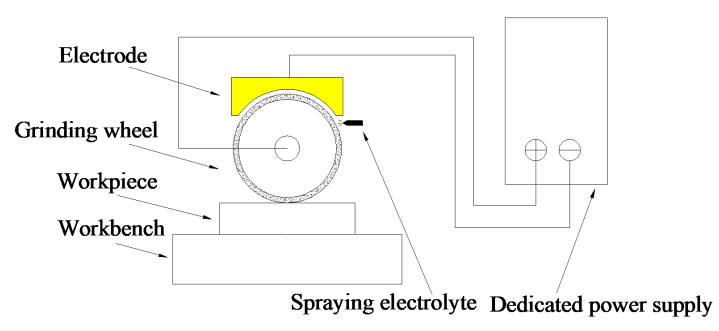

Figure 2: Principle of ELID plane grinding 
tion. The positive electrode of the special power source is connected with the iron-based diamond super-hard abrasive grinding wheel as the anode of the electrolysis reaction, and the negative electrode of the power source is connected with the electrode as the cathode of the electrolysis reaction. And the grinding fluid spraying device is installed between the electrode and the grinding wheel, so that the grinding fluid can be evenly sprayed between the electrode and the grinding wheel to form a whole closed electrolytic reaction circuit, thereby achieving ELID grinding of the workpiece [8-10].

During the ELID grinding process, the metal bond on the surface of the iron-based diamond super hard abrasive grinding wheel and grinding fluid, the anodic dissolution reaction occurs under the action of electrolysis. The metal will detach from the surface of the grinding wheel in the form of metal cations under the anodic dissolution, so that the diamond abrasive grain edge in the abrasive layer of the grinding wheel is exposed to the surface. In addition to the above-mentioned anodic dissolution reaction, during the grinding process, due to the high grinding temperature, the aluminum-based abrasive grains generated by the softening of the aluminum matrix phase in the aluminum-based diamond composite material adhere to the surface of the grinding wheel. These aluminum-based abrasive chips and the grinding fluid will also undergo an anodic dissolution reaction, thereby electrolytic removing the aluminum-based abrasive chips from the surface of the grinding wheel, effectively solving the clogging phenomenon of the grinding wheel caused by the aluminum matrix, and always maintaining the cutting performance of the grinding wheel. At the same time, the dissolved metal cations will chemically react when they encounter the hydroxide ions in the grinding fluid, and form an oxide film, which is then attached to the surface of the grinding wheel to protect it, thereby suppressing the degree of electrolysis and effectively preventing excessive electrolysis of the grinding wheel. Therefore, ELID grinding technology can carry out high-efficiency micro-cutting removal of aluminum-based diamond composites, thus achieving precision grinding of aluminum-based diamond composites $[8-11,14]$.

\section{Factors affecting the surface roughness}

In the ELID grinding process of aluminum-based diamond composites, surface roughness is a core concern of researchers and an important indicator for describing the

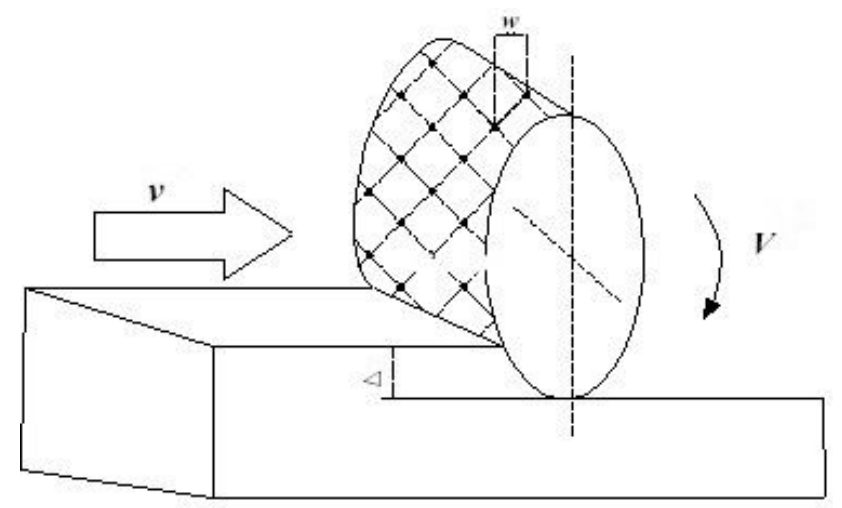

Figure 3: Grinding Model

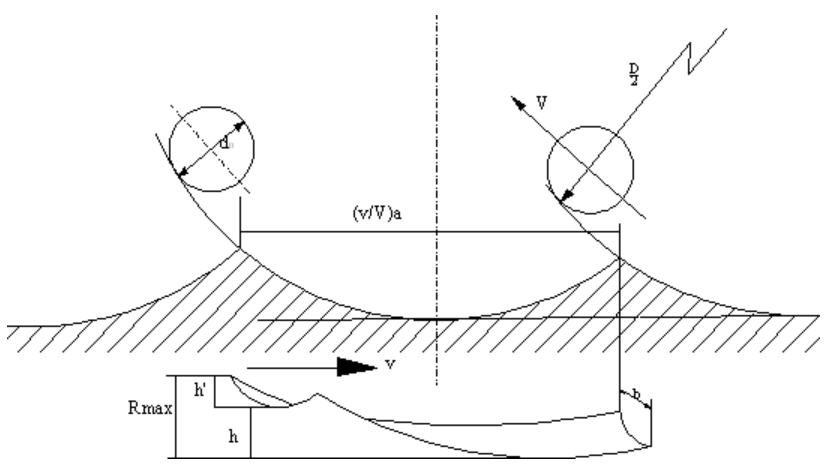

Figure 4: The cutting streak model of the grinding wheel cutting edge

surface quality of workpieces. For aluminum-based diamond composites for electronic packaging, the lower the surface roughness is preferred. Therefore, how to reduce the surface roughness is the goal that is constantly pursued in the processing. Through the establishment of the grinding model, the factors affecting the surface roughness of the aluminum-based diamond composite were investigated. The grinding model is shown in Figure 3. The cutting streak model of the grinding wheel cutting edge is shown in Figure 4.

In order to visually study the grinding wheel grinding form, this paper assumes that the abrasive particles are relatively evenly distributed on the surface of the grinding wheel. It can be calculated that the average moving distance is $(v / V) \Delta$ of the workpiece in any two adjacent abrasive grain cutting-in and cutting-out time intervals.

In the grinding process, the trajectory of the abrasive cutting edge is approximated as an arc, and it can be calculated:

$$
h=\frac{1}{4}\left(\frac{v}{V}\right)^{2} \frac{\Delta^{2}}{D}
$$

In the formula:

$H$ - the height of the residual chips cut by the cutting edge 
on the surface of the workpiece;

$v$ - the speed of the grinding wheel;

$V$ - the moving speed of the workpiece;

$\Delta$ - grinding depth;

$D$ - the diameter of the grinding wheel.

In addition, if there is a uniform streak having a width $b$ in the grinding surfaces, the depth of the streak perpendicular to the grinding direction is $h^{\prime} \ll b$. So the streak depth is approximately:

$$
h^{\prime}=\frac{1}{4} \frac{b^{2}}{d_{0}}
$$

In the formula:

$h^{\prime}$ - the depth of the streak perpendicular to the direction of grinding;

$b$ - uniform strip width;

$d_{0}$ - the average diameter of the abrasive particles;

The surface after grinding is a shape in which many streaks are arranged side by side, so the maximum height value of the surface roughness is:

$$
R_{\max }=\frac{1}{4}\left(\frac{v}{V}\right)^{2} \frac{\Delta^{2}}{D}+\frac{1}{4} \frac{b^{2}}{d_{0}}
$$

In the formula:

$R_{\max }$ - the maximum height of the surface roughness;

It can be concluded from the formula 3 that the maximum surface roughness $R_{\max }$ increases with the increase of the workpiece moving speed and the grinding depth of the grinding wheel, and decreases as the linear speed of the grinding wheel increases. Therefore, the grinding depth, the linear speed of the grinding wheel and the moving speed of the workpiece are important factors affecting the surface roughness of the aluminum-based diamond composite.

\section{Aluminum-based diamond composite ELID grinding test}

\subsection{Grinding test conditions}

Grinding experiments were carried out on the aluminumbased diamond composites with a diamond particlereinforced phase volume fraction of $30 \%$ and a diamond particle size of $50 \mu \mathrm{m}$ using ELID precision grinding technology. The aluminum-based diamond composite material before the experimental processing is shown in Figure 5, and the experimental device and testing equipment are shown in Table 2. Among them, it is necessary to specifically specify the particle size of the grinding wheel. Since
Table 2: Experimental and testing equipment

\begin{tabular}{cl}
\hline $\begin{array}{c}\text { Experimental } \\
\text { testing } \\
\text { equipment }\end{array}$ & Model type \\
\hline Surface Grinder & $\begin{array}{l}\text { Modified MSG-612CNC ultra- } \\
\text { precision forming surface grinder } \\
\text { with ELID module } \\
\text { Grinding of cast iron-based diamond } \\
\text { wheels with a diameter of 180 mm } \\
\text { and 120\# grain size }\end{array}$ \\
power supply & $\begin{array}{l}\text { Self-developed dedicated ELID DC } \\
\text { pulse power supply }\end{array}$ \\
Grinding fluid & $\begin{array}{l}\text { Self-contained ELID grinding fluid for } \\
\text { aluminum-based composites } \\
\text { TR300 roughness shape detector }\end{array}$ \\
Measuring & instrument
\end{tabular}

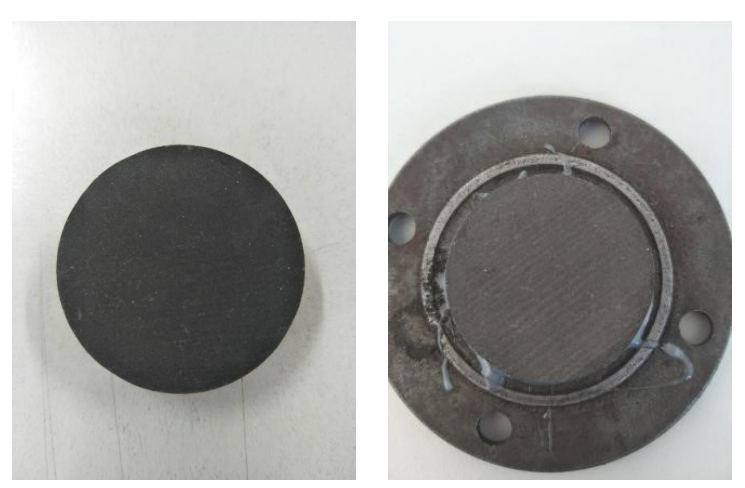

Figure 5: Aluminum-based diamond composite before processing

the particle-reinforced phase of the aluminum-based diamond composite is diamond particles, the abrasive component of the grinding wheel binder is also diamond abrasive grains. After repeated experiments, it was found that the grinding wheel can effectively grind the material only when the particle size of the diamond abrasive grains in the grinding wheel is larger than the particle size of the diamond particles in the material. Otherwise, there will be a phenomenon in which the grinding removal effect is poor, the pits are large, and severe diamond particles are broken and the workpiece is scratched.

\subsection{Grinding test design}

The quadratic orthogonal rotation combination method is an experimental design method with orthogonal, regression, uniform and high saturation. It adjusts the number of trials of the center point $\mathrm{m}_{0}$ to make the regression ro- 
Table 3: Range of values for each test factor

\begin{tabular}{|c|c|c|c|c|c|}
\hline Level & 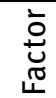 & $\begin{array}{c}\text { Grinding depth } \\
(\mu \mathrm{m})\end{array}$ & $\begin{array}{c}\text { Grinding wheel } \\
\text { speed }(\mathrm{m} / \mathrm{s})\end{array}$ & Duty cycle (\%) & $\begin{array}{l}\text { Electrolytic current } \\
\text { (A) }\end{array}$ \\
\hline Upper level & & 1 & 20 & 20 & 4 \\
\hline Lower level & & 13 & 36 & 100 & 20 \\
\hline
\end{tabular}

tation combination test have certain orthogonality, which belongs to a more advanced experimental design optimization method. Compared with the traditional single factor test and orthogonal test method, the advantages of the regression orthogonal design test are retained. It can greatly simplify the calculation process and simplify the process of testing data. At the same time, it can partially eliminate the correlation between regression coefficients, and can directly seek the optimal region according to the measured values, and carry out simulation analysis from multiple angles. This kind of optimization design method can obtain the precision law when using regression equations for prediction, and it is more systematic and scientific [15-17].

\subsubsection{Test design scheme}

In this test, the grinding test design of aluminum-based diamond composites will be carried out by the quadratic orthogonal rotation combination test method. The surface roughness is selected as the test index. And the grinding depth, linear velocity of the grinding wheel, the duty ratio and the electrolysis current are the four factors that affect the surface roughness. In the experimental design, the upper and lower levels of the four factors are first determined as shown in Table 3.

After determining the upper and lower levels of each factor, calculate the zero level and the change spacing. The formula for calculating the zero level and variation spacing of a factor is:

$$
\begin{gathered}
Z_{0 j}=\left(Z_{1 j}+Z_{2 j}\right) / 2 \\
\Delta_{j}=\left(Z_{2 j}-Z_{0 j}\right) / \gamma \\
\gamma=2^{\frac{p-i}{4}}, \quad i=\left\{\begin{array}{l}
0, \text { Full implementation } \\
1,1 / 2 \text { Implementation } \\
2,1 / 4 \text { Implementation }
\end{array}\right.
\end{gathered}
$$

In the formula:

$j=1,2,3 \ldots, \mathrm{m}$;

$Z_{2 j}$ - the upper level of the jth factor;

$Z_{1 j}$ - the lower level of the jth factor;
$Z_{0 j}-$ Zero level of the jth factor;

$\Delta_{j}$ - the value change interval of the jth factor;

$\gamma$ - the parameter to be determined, which can be calculated from equation 6.

In the design process of the quadratic orthogonal rotation combination test, the test factors are coded, and the coding formula is:

$$
X_{a j}=\left(Z_{a j}-Z_{0 j}\right) / \Delta_{j}
$$

In the formula:

$Z_{\alpha j}$ - the actual level of the jth factor;

$X_{\alpha j}$ - the jth factor specifies the level of each coding.

It can be known from formula 6 that in this test, $\gamma$ is equal to 2, and the upper and lower levels of the above factors are substituted into equations 4 and 5 to obtain the zero level and variation spacing of each factor. Then, the test factor level coding table is obtained according to the formula 7, as shown in Table 4.

Table 4: Test factor level coding table

\begin{tabular}{cccccc}
\hline Level & $\mathrm{Z}_{1}$ & $\mathrm{Z}_{2}$ & $\mathrm{Z}_{3}$ & $\mathrm{Z}_{4}$ & Coding \\
\hline$Z_{1 j}$ & 1 & 20 & 20 & 4 & -2 \\
$Z_{0 j}-\Delta_{j}$ & 4 & 24 & 40 & 8 & -1 \\
$Z_{0 j}$ & 7 & 28 & 60 & 12 & 0 \\
$Z_{0 j}+\Delta_{j}$ & 10 & 32 & 80 & 16 & +1 \\
$Z_{2 j}$ & 13 & 36 & 100 & 20 & +2 \\
$\Delta j=\frac{\left(Z_{2 j}-Z_{0 j}\right)}{\gamma}$ & 3 & 4 & 20 & 4 & - \\
\hline
\end{tabular}

36 sets of tests were designed according to the theory of quadratic orthogonal rotation combined design [18]. The surface roughness of the aluminum-based diamond composite obtained under the combination of each set of test parameters was measured using a TR300 roughness shape measuring instrument, and each group was measured 12 times. The test should minimize errors in instrument measurement errors and uncertainties in processing. From each set of measured surface roughness values, the maximum and minimum values were removed, and then the average value was taken as the surface roughness result under the combination of the process parameters. The experimental design and test result data of 


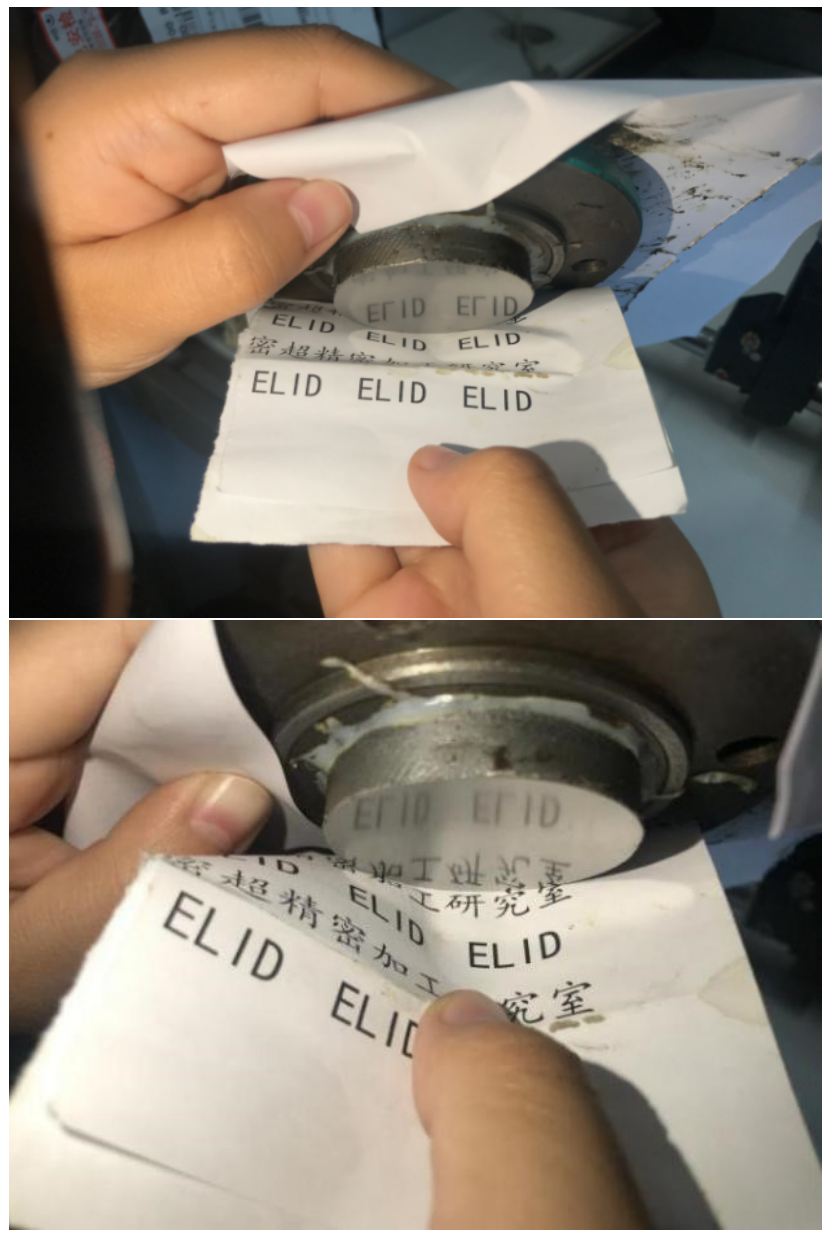

Figure 6: Processed aluminum-based diamond composite

the aluminum-based diamond composite ELID precision grinding quadratic orthogonal rotation combination are shown in Table 5. The processed aluminum-based diamond composite material is shown in Figure 6.

\subsubsection{Test of mathematical model}

According to the principle of quadratic regression analysis $[16,18]$, the quadratic mathematical regression model of surface roughness with four dependent variables is:

$$
y=b_{0}+\sum_{i} b_{i} x_{i}+\sum_{i<j} b_{i j} x_{i} x_{j}+\sum_{i} b_{i i} x_{i}^{2}
$$

According to the regression model and the test result data in Table 5, the estimated values of the regression coefficients are obtained by DPS, and the quadratic regression equation of the surface roughness is obtained:

$$
\begin{aligned}
Y & =153.25000+7.58333 X_{1}-20.66667 X_{2} \\
& -0.75000 X_{3}-2.16667 X_{4}+3.22917 X_{1}{ }^{2}
\end{aligned}
$$

$$
\begin{aligned}
& +4.72917 X_{2}^{2}+3.60417 X_{3}^{2}+4.35417 X_{4}^{2} \\
& -6.37500 X_{1} X_{2}+1.37500 X_{1} X_{3}-0.25000 X_{1} X_{4} \\
& -0.75000 X_{2} X_{3}-0.62500 X_{2} X_{4}+1.12500 X_{3} X_{4}
\end{aligned}
$$

After obtaining the regression equation, it is statistically tested to judge the reliability of the regression equation and the goodness of fit to the real situation. The variance analysis of the surface roughness test results is shown in Table 6.

It can be seen from Table 6 that $F_{1}=1.78727<$ $F_{0.01}(10,11)=4.54$, that is, $F_{1}$ is not significant at the 0.01 level. It is indicated that the losing fitting sum of squares at this significance level does not contain nonnegligible factors that affect the test results. That is, the regression equation has a good fit.

It can be seen from Table 6 that $F_{2}=23.5982>$ $F_{0.01}(14,21)=3.07$, reaching a very significant level. It is indicated that the four dependent variables of grinding wheel linear velocity, grinding depth, dutycycle and electrolysis current have a significant effect on the surface roughness of aluminum-based diamond composites.That is, the regression equation model is established.

As can be seen from Table 6, $F_{3}=32.4451>$ $F_{0.01}(14,11)=4.30$, reaching a very significant level.It is considered that the regression equation results are reliable for each test factor and can be used to guide the actual and predict surface roughness.

The decision coefficient $R_{2}$ is the ratio of regression square sum to total square sum $\left(0 \leq R_{2} \leq 1\right)$. Through the inspection, the coefficient of determination $R_{2}$ of the aluminum-based diamond composite ELID precision grinding surface roughness quadratic regression model is $R_{2}=0.9402$. The influence of the four dependent variables of grinding depth, grinding wheel linear velocity, duty cycle and electrolysis current on the surface roughness is $94.02 \%$. That is, the regression equation has a good fit to the actual measurement.

The variance analysis of the quadratic regression model shows that these differences are extremely significant $(p<0.01)$, including the linear term of grinding depth and linear velocity of the grinding wheel, the quadratic term of linear velocity of the grinding wheel, the duty cycle and the electrolysis current, and the interaction between the grinding depth and the linear speed of the grinding wheel.The quadratic term of the grinding depth reached a significant level $(p<0.05)$.Through the significance testing of the regression equation, the order of influence on the surface roughness of the aluminum-based diamond composite ELID precision grinding is $X_{2}>X_{1}>$ $X_{4}>X_{3}$, that is, the grinding wheel line speed $>$ grinding depth $>$ electrolysis current $>$ duty ratio. Therefore, 
Table 5: Design and test results of quadratic orthogonal rotation combination test

\begin{tabular}{|c|c|c|c|c|c|c|c|c|c|}
\hline Test number & $\mathrm{X}_{1}$ & $x_{2}$ & $x_{3}$ & $X_{4}$ & $\mathrm{z}_{1}$ & $\mathrm{Z}_{2}$ & $Z_{3}$ & $\mathrm{Z}_{4}$ & Roughness/nm \\
\hline 1 & 1 & 1 & 1 & 1 & 10 & 32 & 80 & 16 & 153 \\
\hline 2 & 1 & 1 & 1 & -1 & 10 & 32 & 80 & 8 & 145 \\
\hline 3 & 1 & 1 & -1 & 1 & 10 & 32 & 40 & 16 & 150 \\
\hline 4 & 1 & 1 & -1 & -1 & 10 & 32 & 40 & 8 & 147 \\
\hline 5 & 1 & -1 & 1 & 1 & 10 & 24 & 80 & 16 & 211 \\
\hline 6 & 1 & -1 & 1 & -1 & 10 & 24 & 80 & 8 & 204 \\
\hline 7 & 1 & -1 & -1 & 1 & 10 & 24 & 40 & 16 & 207 \\
\hline 8 & 1 & -1 & -1 & -1 & 10 & 24 & 40 & 8 & 205 \\
\hline 9 & -1 & 1 & 1 & 1 & 4 & 32 & 80 & 16 & 147 \\
\hline 10 & -1 & 1 & 1 & -1 & 4 & 32 & 80 & 8 & 144 \\
\hline 11 & -1 & 1 & -1 & 1 & 4 & 32 & 40 & 16 & 154 \\
\hline 12 & -1 & 1 & -1 & -1 & 4 & 32 & 40 & 8 & 151 \\
\hline 13 & -1 & -1 & 1 & 1 & 4 & 24 & 80 & 16 & 187 \\
\hline 14 & -1 & -1 & 1 & -1 & 4 & 24 & 80 & 8 & 174 \\
\hline 15 & -1 & -1 & -1 & 1 & 4 & 24 & 40 & 16 & 185 \\
\hline 16 & -1 & -1 & -1 & -1 & 4 & 24 & 40 & 8 & 180 \\
\hline 17 & 2 & 0 & 0 & 0 & 13 & 28 & 60 & 12 & 141 \\
\hline 18 & -2 & 0 & 0 & 0 & 1 & 28 & 60 & 12 & 182 \\
\hline 19 & 0 & 2 & 0 & 0 & 7 & 36 & 60 & 12 & 201 \\
\hline 20 & 0 & -2 & 0 & 0 & 7 & 20 & 60 & 12 & 134 \\
\hline 21 & 0 & 0 & 2 & 0 & 7 & 28 & 100 & 12 & 164 \\
\hline 22 & 0 & 0 & -2 & 0 & 7 & 28 & 20 & 12 & 162 \\
\hline 23 & 0 & 0 & 0 & 2 & 7 & 28 & 60 & 20 & 164 \\
\hline 24 & 0 & 0 & 0 & -2 & 7 & 28 & 60 & 4 & 168 \\
\hline 25 & 0 & 0 & 0 & 0 & 7 & 28 & 60 & 12 & 152 \\
\hline 26 & 0 & 0 & 0 & 0 & 7 & 28 & 60 & 12 & 161 \\
\hline 27 & 0 & 0 & 0 & 0 & 7 & 28 & 60 & 12 & 147 \\
\hline 28 & 0 & 0 & 0 & 0 & 7 & 28 & 60 & 12 & 151 \\
\hline 29 & 0 & 0 & 0 & 0 & 7 & 28 & 60 & 12 & 156 \\
\hline 30 & 0 & 0 & 0 & 0 & 7 & 28 & 60 & 12 & 147 \\
\hline 31 & 0 & 0 & 0 & 0 & 7 & 28 & 60 & 12 & 155 \\
\hline 32 & 0 & 0 & 0 & 0 & 7 & 28 & 60 & 12 & 146 \\
\hline 33 & 0 & 0 & 0 & 0 & 7 & 28 & 60 & 12 & 156 \\
\hline 34 & 0 & 0 & 0 & 0 & 7 & 28 & 60 & 12 & 163 \\
\hline 35 & 0 & 0 & 0 & 0 & 7 & 28 & 60 & 12 & 148 \\
\hline 36 & 0 & 0 & 0 & 0 & 7 & 28 & 60 & 12 & 157 \\
\hline
\end{tabular}

under the significant level of $\alpha=0.1$, the insignificant term is eliminated, and the simplified regression equation is $[19,20]$ :

$$
\begin{aligned}
Y & =153.25000+7.58333 X_{1}-20.66667 X_{2} \\
& +3.22917 X_{1}{ }^{2}+4.72917 X_{2}{ }^{2}+3.60417 X_{3}{ }^{2} \\
& +4.35417 X_{4}{ }^{2}-6.37500 X_{1} X_{2}
\end{aligned}
$$

\subsubsection{Single factor effect analysis}

The influence law of grinding depth, grinding wheel linear speed, duty ratio and electrolysis current on surface roughness is shown in Figure 7. 
Table 6: Surface roughness test results analysis of variance

\begin{tabular}{cccccc}
\hline Factor & Sum of square & Degree of freedom & Mean square & Partial correlation & $P$ value \\
\hline$X_{1}$ & 1380.1667 & 1 & 1380.1667 & 0.7738 & 0.0001 \\
$X_{2}$ & 10250.666 & 1 & 10250.666 & -0.9577 & 0.0001 \\
$X_{3}$ & 13.5000 & 1 & 13.5000 & -0.1200 & 0.5856 \\
$X_{4}$ & 112.6667 & 1 & 112.6667 & 0.3296 & 0.1246 \\
$X_{1}^{2}$ & 333.6806 & 1 & 333.6806 & 0.5150 & 0.0119 \\
$X_{2}^{2}$ & 715.6806 & 1 & 715.6806 & 0.6605 & 0.0006 \\
$X_{3}^{2}$ & 415.6806 & 1 & 415.6806 & 0.5569 & 0.0058 \\
$X_{4}^{2}$ & 606.6806 & 1 & 606.6806 & 0.6294 & 0.0013 \\
$X_{1} X_{2}$ & 650.2500 & 1 & 650.2500 & -0.6426 & 0.0009 \\
$X_{1} X_{3}$ & 30.2500 & 1 & 30.2500 & 0.1780 & 0.4165 \\
$X_{1} X_{4}$ & 1.0000 & 1 & 1.0000 & -0.0329 & 0.8816 \\
$X_{2} X_{3}$ & 9.0000 & 1 & 9.0000 & -0.0982 & 0.6558 \\
$X_{2} X_{4}$ & 6.2500 & 1 & 6.2500 & -0.0819 & 0.7101 \\
$X_{3} X_{4}$ & 20.2500 & 1 & 20.2500 & 0.1464 & 0.5051 \\
Regression & 14545.722 & 14 & 1038.9802 & $F_{2}=23.5982$ & 0.0001 \\
Residual & 924.5833 & 21 & 44.0278 & - & - \\
Lose & 572.3333 & 10 & 57.2333 & $F_{1}=1.78727$ & 0.1260 \\
fitting & & & & & \\
Error & 352.2500 & 11 & 32.0227 & $F_{3}=32.4451$ & - \\
Sum & 15470.3056 & 35 & - & - & - \\
\hline
\end{tabular}

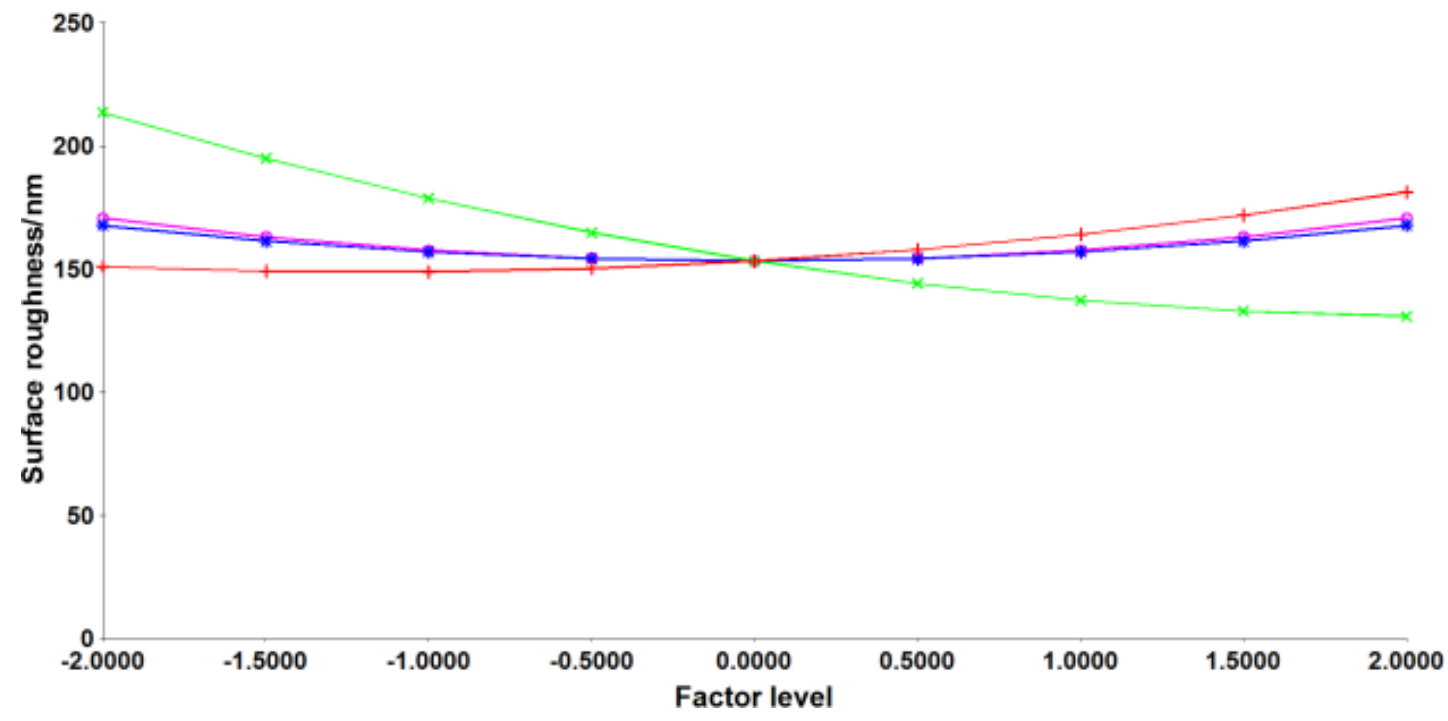

Figure 7: Effect of various factors on surface roughness

\section{(1) Analysis of the influence of grinding depth on surface roughness}

It can be seen from Figure 8 that in the ELID grinding process of the aluminum-based diamond composite material, the surface roughness value is increased from 148 $\mathrm{nm}$ to $181 \mathrm{~nm}$ when the grinding depth is increased from the horizontal-2 $(1 \mu \mathrm{m})$ to the horizontal $2(13 \mu \mathrm{m})$. That is, within a certain range, the surface roughness value in- creases as the grinding depth increases. This will cause the grinding wheel and the workpiece to be deformed due to the increased force and the grinding removal ability is reduced.The surface of the workpiece is broken and detached, and defects such as pits and scratches are generated.Therefore, the surface grinding quality of the workpiece deteriorates. 


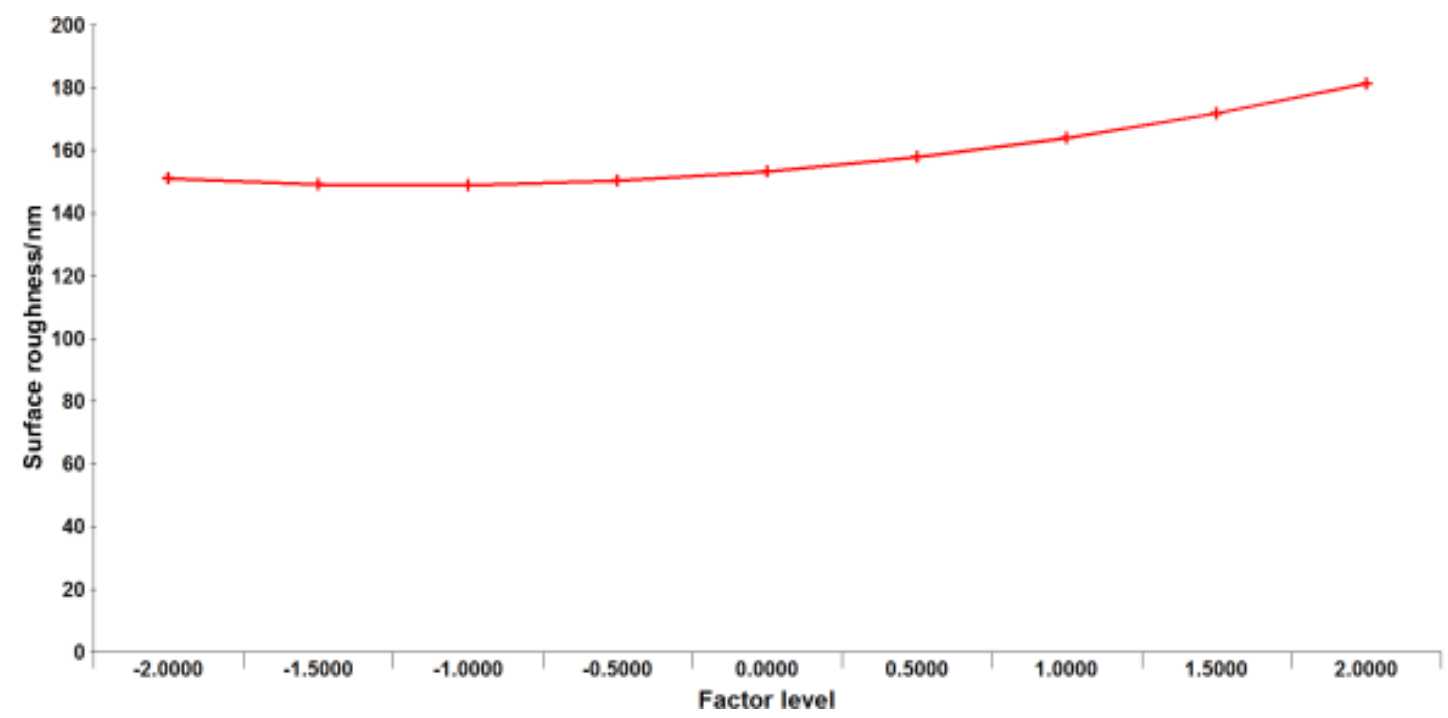

Figure 8: The effect of grinding depth on surface roughness

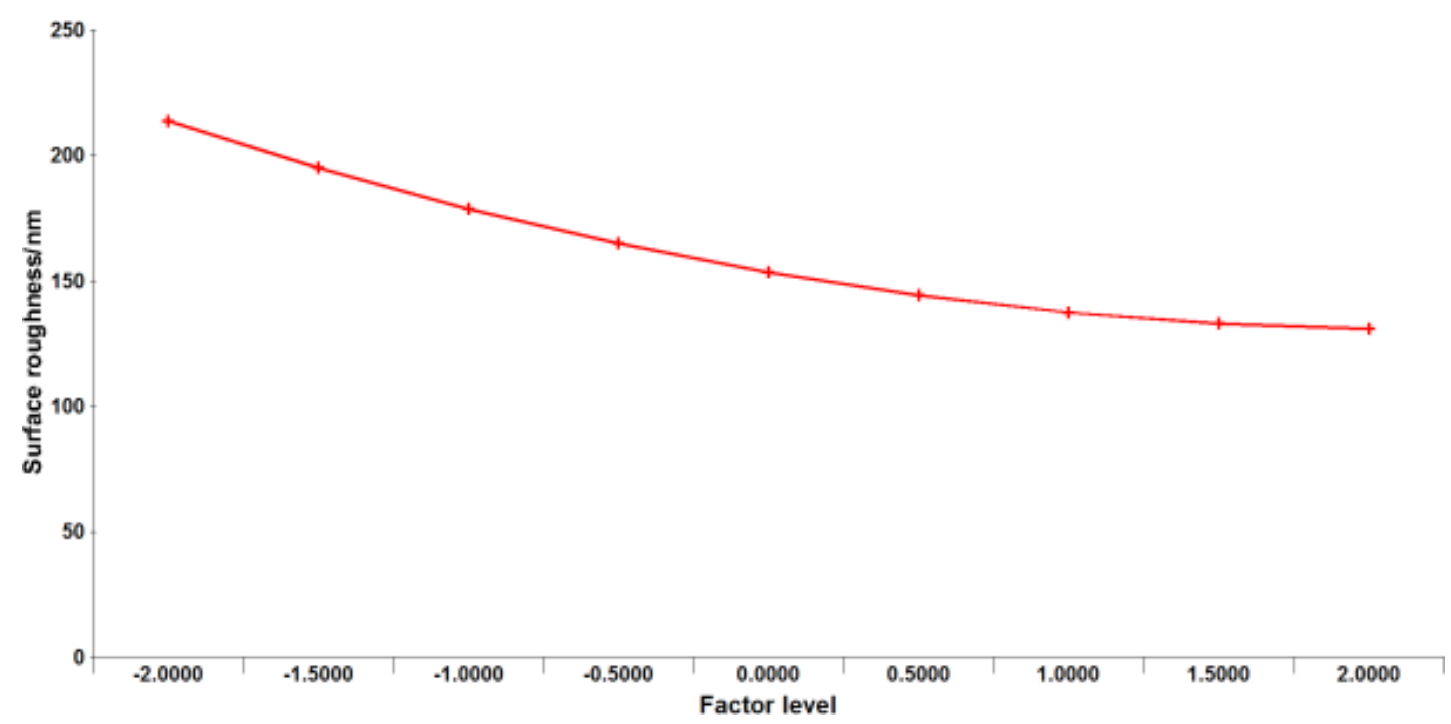

Figure 9: The effect of wheel speed on surface roughness

\section{(2) Analysis of the influence of the linear speed of the grinding wheel on the surface roughness}

It can be seen from Figure 9 that in the process of ELID grinding of aluminum-based diamond composites, the surface roughness value is reduced from $130 \mathrm{~nm}$ to $213 \mathrm{~nm}$ when the linear velocity of the grinding wheel is increased from horizontal-2 $(20 \mathrm{~m} / \mathrm{s})$ to horizontal $2(36 \mathrm{~m} / \mathrm{s})$. That is, within a certain range, the surface roughness value decreases as the linear velocity of the grinding wheel increases. Because the linear speed of the grinding wheel increases during the ELID grinding process, the number of abrasive grains in the grinding area per unit area will increase, and the maximum undeformed cutting thickness of the single abrasive grain becomes thinner. Thereby the grinding depth and the cutting force of the abrasive grains are reduced. At the same time, due to the oxidized film forming characteristics in the ELID grinding process, the oxide film is continuously generated, and the abrasive grains are subjected to high-speed grinding and polishing of the aluminum-based diamond composite material at a large grinding wheel linear velocity.Therefore, the surface grinding quality of the workpiece becomes better and the surface roughness value decreases. 


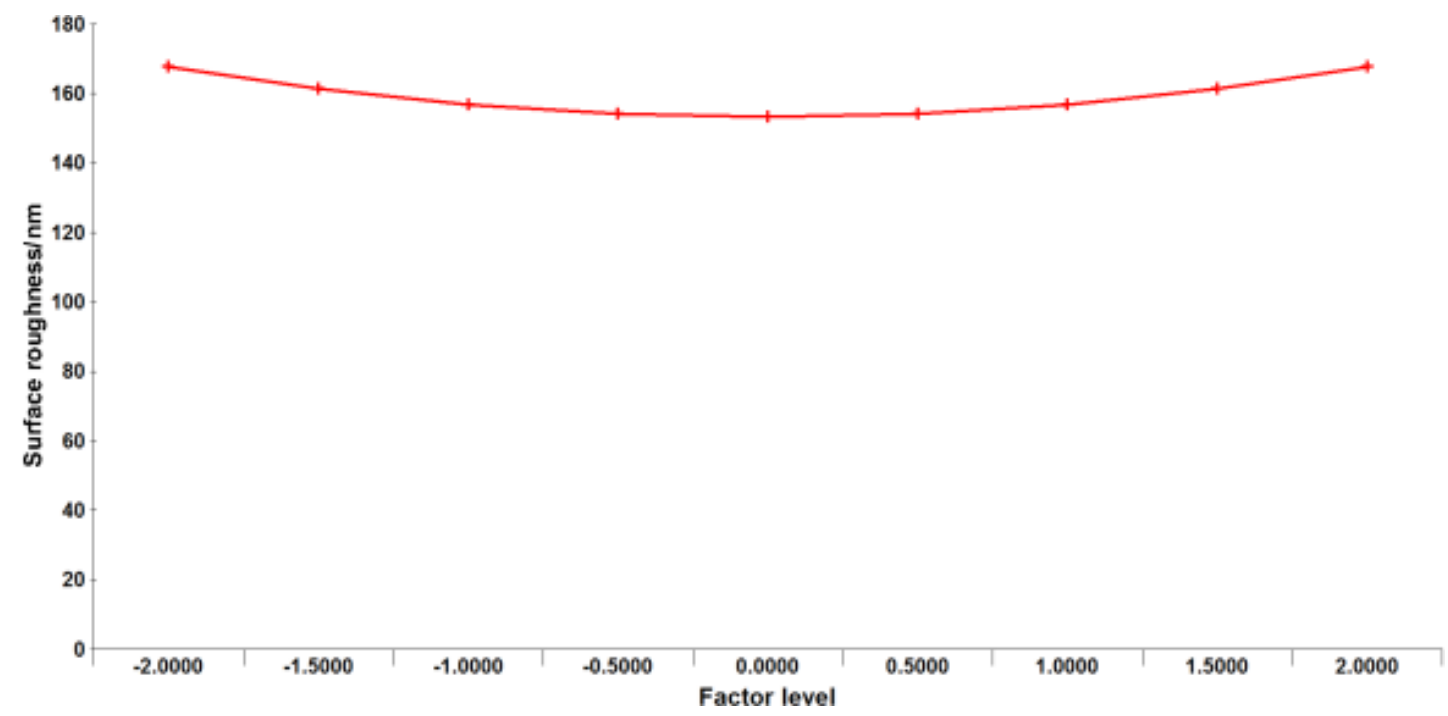

Figure 10: The effect of duty cycle on surface roughness

\section{(3) Analysis of the influence of duty ratio on surface roughness}

It can be seen from Figure 10 that the the surface roughness decreases from $167 \mathrm{~nm}$ to $153 \mathrm{~nm}$ and then increases to 167 $n m$ when the duty ratio is increased from the level $-2(20 \%)$ to the level $0(60 \%)$ and then to the level $2(100 \%)$ during the ELID grinding process of the aluminum-based diamond composite material. That is, within a certain range, the surface roughness value decreases first and then increases as the duty ratio increases. Because during the ELID grinding process, the current density per unit area of the grinding wheel is small and the oxidation film forming property is weak under a certain electrolysis voltage, and the oxide film does not have a polishing effect on the workpiece. When the duty ratio is increased to $50 \%$, the oxidized electrolytic film forming property is enhanced, and the oxide film can perform precision machining of the workpiece by grinding and polishing, thereby improving the surface processing quality of the workpiece and reducing the surface roughness value. However, when the duty ratio continues to increase, the current density per unit area continues to increase, and the grinding wheel generates excessive electrolysis, which causes the abrasive particles to fall off and the excessive generation of the oxide film, resulting in a decrease in the grinding performance of the grinding wheel. Therefore, the surface quality of the workpiece is deteriorated and the roughness value is increased.

\section{(4) Analysis of the influence of electrolysis current on surface roughness}

It can be seen from Figure 11 that the the surface roughness decreases from $170 \mathrm{~nm}$ to $153 \mathrm{~nm}$ and then increases to $170 \mathrm{~nm}$ when the electrolysis current is increased from the level $-2(4 \mathrm{~A})$ to the level $0(12 \mathrm{~A})$ and then to the level 2 $(20 \mathrm{~A} \%)$ during the ELID grinding process of the aluminumbased diamond composite material. That is, within a certain range, the surface roughness value decreases first and then increases as the duty ratio increases. Because this experiment uses a DC pulse power supply with a constant current source, the electrolysis current increases, the current density per unit area of the grinding wheel increases, and the dissolution rate and electrolytic film forming characteristics of the metal bond on the surface of the grinding wheel increase. More abrasive sharp edges expose the surface and improve grinding performance. At the same time, the oxide film can polish the surface of the aluminumbased diamond composite material, the surface grinding quality of the workpiece becomes better, and the surface roughness value decreases. However, as the electrolysis current continues to increase, the electrolysis speed of the metal bond grinding wheel is too fast, the abrasive grains are largely detached due to excessive electrolysis, and the grinding performance of the grinding wheel is lowered, resulting in deterioration of the surface quality of the machined surface. 


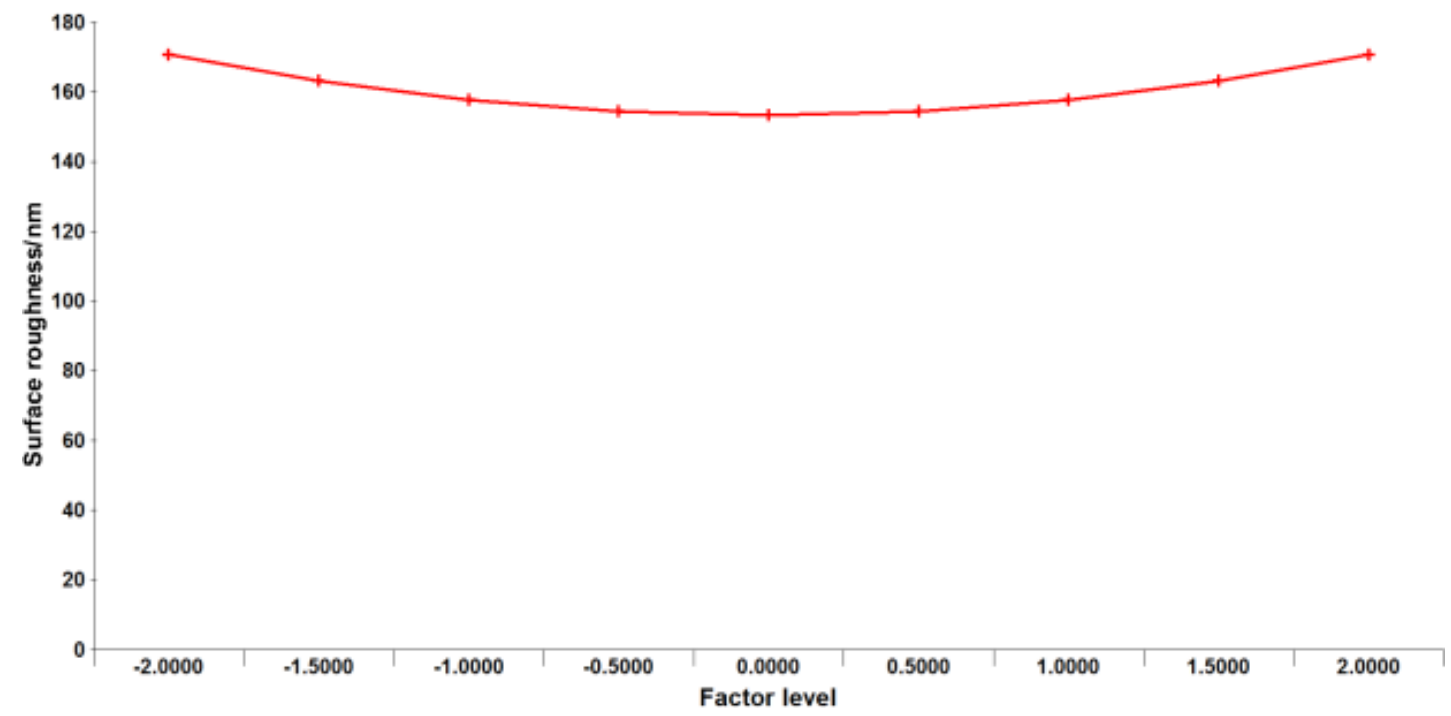

Figure 11: The effect of electrolysis current on surface roughness

\subsubsection{Analysis of interaction effects between two factors}

According to the level of significance in Table 6, only the interaction between the grinding depth and the linear velocity of the grinding wheel reached a very significant level $(p<0.01)$. Using regression equation and DPS software, the influence of grinding depth and grinding wheel linear velocity on surface roughness is shown in Figure 12. The interaction between various factors can be reflected in threedimensional space [19].

In the horizontal range of $(-2,2)$, when the linear speed of the grinding wheel is constant, the surface roughness value increases with the increase of the grinding depth. When the grinding depth is fixed, the surface roughness decreases with the increase of the linear velocity of the grinding wheel. When the grinding depth is at 1 level $(10 \mu \mathrm{m})$ and the linear speed of the grinding wheel is at 2 levels $\left(36 \mathrm{~m} \cdot \mathrm{s}^{-1}\right)$, the lowest point is reached, the surface roughness reaches a minimum.

\subsubsection{Optimization of ELID grinding process parameters}

The process parameters of grinding depth, grinding wheel linear velocity, duty cycle and electrolysis current are optimized by quadratic regression model. Using the regression model as the objective function, the range of the variables $\mathrm{X}_{1}, \mathrm{X}_{2}, \mathrm{X}_{3}$, and $\mathrm{X}_{4}$ is set to $(-2,2)$, and the objective function is optimized using the LINGO software. Using the coding formula (3-4), the optimized process parameters are: grinding depth $9.3 \mu \mathrm{m}$, grinding wheel linear speed $36 \mathrm{~m} / \mathrm{s}$,

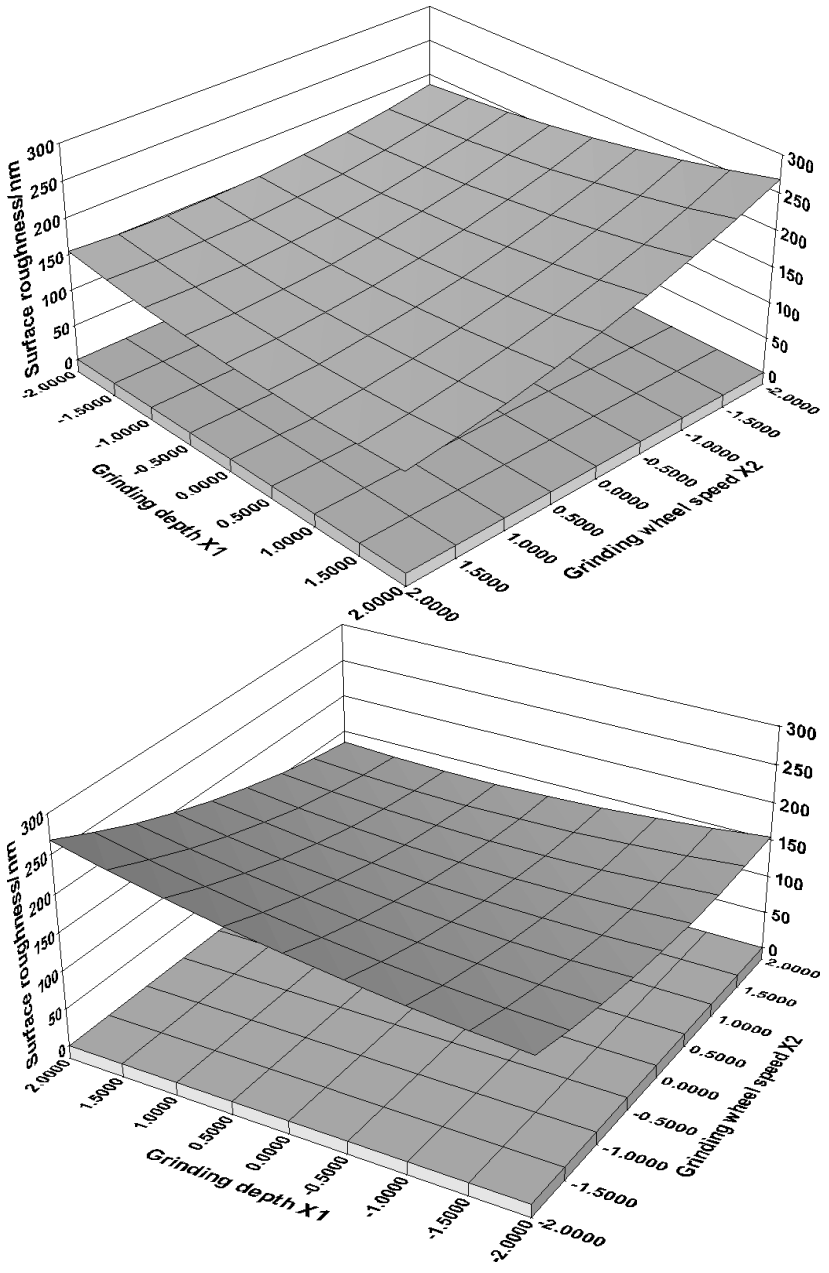

Figure 12: Effect of grinding depth and grinding wheel speed on surface roughness duty ratio $63.7 \%$, and electrolysis current 11.5A. Substitut- 
ing the combination of process parameters into the regression equation yields $\mathrm{Y}=128.6 \mathrm{~nm}$. The ELID grinding parallel test of the workpiece was carried out under the optimized combination of process parameters, and the average surface roughness was $125 \mathrm{~nm}$. The relative error between the test results and the surface roughness value predicted by the regression equation is $3.6 \mathrm{~nm}$. Therefore, the combination of process parameters and surface roughness values obtained by the quadratic orthogonal rotation combination design method are reliable.

\section{Conclusions}

In this paper, the ELID grinding technology is used to grind the aluminum-based diamond composites for electronic packaging, and the following conclusions are drawn:

1. The quadratic regression mathematical model of surface roughness is obtained by quadratic orthogonal rotation combination method and DPS software, and the equation is tested for significance. The order of the influence of four process parameters on the surface roughness of ELID precision grinding of aluminum-based diamond composites is as follows: grinding wheel line speed>grinding depth>electrolysis current $>$ duty ratio. The effect of the line speed and grinding depth on the surface roughness is extremely significant.

2. Through the results of the quadratic orthogonal rotation combination test and DPS software analysis: the surface roughness value increases with the increase of the grinding depth; decreases with the increase of the grinding wheel linear velocity; with the duty cycle and the electrolysis current Increase, first decrease and then increase.

3. Using LINGO software and coding formula, the optimized process parameters are: grinding depth $9.3 \mu \mathrm{m}$, grinding wheel linear speed $36 \mathrm{~m} / \mathrm{s}$, duty ratio $63.7 \%$, and electrolysis current 11.5A. A processed surface having a surface roughness of $125 \mathrm{~nm}$ was obtained by performing an ELID grinding experiment using an optimized combination of process parameters. The test results are similar to those predicted by the regression equation, and the relative error is 3.6 nm.

\section{References}

[1] J. H. Wu, H. L. Zhang, Y. Zhang, J. W. Li, X.T. Wang. Mechanical properties of diamond particle reinforced aluminum matrix composites [J]. Journal of Functional Materials, 2012, 43(23):3308$3311+3315$.

[2] Z. Yang, S. C. Tan, K. H. Yang. Experimental Research on 3D Printing Metal Matrix Diamond Composites [J]. Diamond and Abrasives Engineering, 2018, 38 (01): 50-54.

[3] Z. L. Yang, X. B. He, A. Ma, M. Wu, L. Zhang, R. J. Liu, H. F. Hu, Y. Z. Zhang , X. H. Qu . Study on Near Net Forming of Diamond/SiC Composites [J]. Rare Metal Materials and Engineering, 2013, 42 (S1): 244-247.

[4] Z. W. Zhong, N. P. Hung, Diamond turning and grinding of aluminum-based metal matrix composites [J]. Materials and Manufacturing Processes, 2000, 15(06):853-865.

[5] S. T. Huang; X. L. Yu, A study of grinding forces of SiCp/Al composites [J]. International Journal of Advanced Manufacturing Technology, 2018, 94 (9-12) : 3633-3639.

[6] L. Xin, X. Tian, W. S. Yang, G. Q. Chen, Enhanced stability of the Diamond/A1 composites by $W$ coatings prepared by the magnetron sputtering method [J]. Journal of Alloys and Compounds, 2018, 763: 305-313.

[7] W. S. Yang, G. Q. Chen, P. P. Wan, J. Qiao, Enhanced thermal conductivity in Diamond/Aluminum composites with tungsten coatings on diamond particles prepared by magnetron sputtering method []]. Journal of Alloys and Compounds, 2017, 726: 623-631.

[8] J. L. Guan, J. W. Fan, M. C. Min. Application of ELID grinding technology in precision ultra-precision machining of hard and brittle materials, Journal of Beijing University of Technology, 2001, 27(4): 486-488.

[9] J. L. Guan, D. M. Guo, Z. J. Yuan. ELID mirror grinding wheel oxide film formation mechanism []]. China Mechanical Engineering, 1999, 10 (6): 630-632.

[10] J. L. Guan, L. Zhu, L. Chen, X. Q. Ma, X. H. Zhang. ELID Precision Machining Process of SiCp/Al Composites [J]. Journal of Beijing Polytechnic University, 2015, 41(06): 823-829.

[11] X. L. Yu, S. T. Huang, L. F. Xu. ELID grinding characteristics of $\mathrm{SiCp} / \mathrm{Al}$ composites [J]. The International Journal of Advanced Manufacturing Technology, 2016, 86:5-8.

[12] G. L. Guan, L. Y. Zhang, S. J. Liu, Y. Yang, Z. Y. Hu, Y. Zhang. Study on Precision Grinding of $\mathrm{SiC}_{P} / \mathrm{Al}$ Composites with Different Volume Fractions [J]. Tool Technology, 2019, 53(07): 23-26.

[13] H. Feng, J. K. Yu, C. Xue, M. H. Ma. Microstructure and thermal expansion properties of diamond aluminum composites for electronic packaging [J]. Thermal Processing Technology, 2010 (14): 59-63.

[14] J. C. Kuai, Ardashev. DV, H. L. Zhang. Study of alpha- $\mathrm{Fe}_{2} \mathrm{O}_{3}$ formation and its measurement in oxide films of wheel surface during ELID grinding process [J]. Modern Physics Letters, 2017, 31(4).

[15] Y. L. Zhou. Process and performance of pulsed electrodeposited Ni-W-P composite coating [D]. China University of Petroleum (East China), 2015.

[16] L. Q. Ren. Regression design and its optimization [M]. Science Press, 2009: 1-7.

[17] G. H. Rong, Y. C. Ning. Evaluation of optimal straw incorporation characteristics based on quadratic orthogonal rotation combination design [J]. Journal of Agricultural Science, 2018, 156:367-377. 
[18] Q. Y. Tang. DPS data processing system [M]. Science Press, 2007: 846-847.

[19] B. Z. Li, S. Z. Su, Z. L. Wang. Optimization of Extraction Process of Papaya Polysaccharide by Quadratic Regression Orthogonal Rotation Combination Design [J]. Light Industry Technology, 2018, 34(09):10-13+65.
[20] X. Y. Ye, Q. X. Liu. Optimization of Boletus Protein Extraction Process by Quadratic Orthogonal Rotation Combination Design [J]. Journal of Nuclear Agricultural Sciences, 2017, 31(04):728735. 